
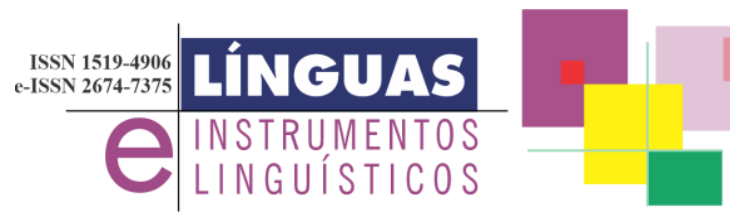

DOI: $10.20396 /$ lil.v24i48.8666994

\title{
Jair Bolsonaro e metaforização de (sem) partido no discurso jornalístico
}

\section{Jair Bolsonaro and the metaphorization of (without) a party in journalistic discourse}

\author{
Vinícius Brito* \\ UNICAMP
}

Resumo: Eleito $38^{\circ}$ presidente do Brasil, Jair Bolsonaro enfrentou a primeira crise governamental no segundo mês de mandato. Ao longo de 2019, a "crise das candidaturas laranjas" do Partido Social Liberal, ou "Laranjal do PSL", levou à saída dele do partido com o qual se elegeu à Presidência. Nessas condições de produção, nos perguntamos como o discurso sobre o atual presidente da República funciona no discurso jornalístico, tomando como entrada no arquivo o "Laranjal do PSL", entre outubro e novembro de 2019. Para isso, analisamos, com princípios e procedimentos da Análise do Discurso, formulações sobre "partido" e Bolsonaro no website da Folha de São Paulo, situando o funcionamento do político no discurso sobre a política e compreendendo como manuais de redação jornalística, na relação com instrumentos linguísticos, produzem uma normatização do dizer sobre Jair Bolsonaro "sem partido" no jornalismo corporativo brasileiro.

Palavras-chave: Jair Bolsonaro, Discurso jornalístico, Partido, Instrumentos linguísticos.

Abstract: Elected 38th president of Brazil, Jair Bolsonaro faced the first government crisis in his second month in office. Throughout 2019, 
the "crisis of orange candidacies" of the Social Liberal Party, or "Laranjal do PSL", implied his departure from the party with which he was elected President. Under these conditions of production, we asked how the discourse about the current president of the Republic means in the press, taking the "Laranjal do PSL" as an entry in the archive, between October and November 2019. With principles and procedures of Discourse Analysis, we analyze formulations about "party" and Bolsonaro on the Folha de São Paulo website, situating the functioning of the politician in the discourse on politics and understanding how journalistic writing manuals, in relation to linguistic instruments, produce a standardization of the saying about Jair Bolsonaro "without a party" in the Brazilian corporate journalism.

Keywords: Jair Bolsonaro, Journalistic discourse, Party, Linguistic instruments.

Bolsonaro então pediu que a imagem não fosse divulgada. "Oh, cara, não divulga isso não, pô. $O$ cara tá queimado pra caramba lá. Vai queimar o meu filme também. Esquece esse cara, esquece o partido".

Folha de S. Paulo, 8 out. 2019.

Após as Jornadas de Junho de $2013^{1}$ e as eleições nacionais para deputado estadual e federal, senador, vice-presidente e presidente em 2014, o Brasil viu se consolidar na política institucional uma onda conservadora, na articulação de uma força social "economicamente liberal, moralmente reguladora, securitariamente punitiva e socialmente intolerante" (ALMEIDA, 2019). Os políticos conservadores foram encabeçados, em grande medida, pela Bancada do Boi, da Bíblia e da Bala, com um crescimento de $25 \%$ de ex-policiais eleitos para os cargos de deputado estadual ou federal em 2014, além de um aumento expressivo no número de parlamentares ligados aos setores militar, religioso e rural àquele ano no Congresso (CIOCCARI, PERSICHETTI, 2018). Essa face do conservadorismo creditou à figura de Bolsonaro a possibilidade de ampliar uma guinada eleitoral à direita, afetada pelos efeitos da Operação Lava Jato, cuja promessa era varrer 
os corruptos da cena política brasileira (STEFANONI, 2018), e pelo declínio dos governos de esquerda na América Latina, na década de 2010, envolvidos em casos de corrupção (ALMEIDA, 2019).

Nesta conjuntura histórica, Jair Bolsonaro ${ }^{2}$ - capitão reformado eleito uma vez para o cargo de vereador na Câmara Municipal do Rio de Janeiro, de 1989 a 1991, e sete vezes para o de deputado federal pelo Rio de Janeiro, de 2003 a 2018 - se tornou, entre 2013 e 2014, um dos principais nomes para eleitores simpáticos à redução da maioridade penal e à ampliação da posse de armas de fogo no país (CIOCCARI, PERSICHETTI, 2018), tendo repercutido declarações racistas e misóginas em inúmeros momentos. Podemos relembrar, por exemplo, uma palestra no clube Hebraica do Rio de Janeiro, em 5 de abril de 2017, quando o então deputado federal pelo estado fluminense formulou ao público presente: "Eu tenho cinco filhos. Foram quatro homens, a quinta eu dei uma fraquejada e veio uma mulher", em um gesto interpretado fortemente como de aversão às mulheres. No mesmo dia, o político prometeu extinguir " "todas as reservas indígenas e comunidades quilombolas do país caso seja eleito em 2018", conforme Cioccari e Persichetti (2018, p. 208-209). Em outubro de 2017, Bolsonaro seria condenado pela $26^{\mathrm{a}}$ Vara Federal do Rio de Janeiro a pagar indenização de $\mathrm{R} \$ 50$ mil por danos morais à população negra brasileira.

Assim, se havia em 2013 e 2014 um certo consenso, imaginariamente fabricado, de que os militares não teriam força para uma intervenção no país, sendo os grupos intervencionistas bastante reprimidos e até expulsos das Jornadas de Junho, "no transcorrer da crise [política e econômica do Governo Dilma Rousseff], os militares foram ocupando espaços no sistema político com a aprovação da opinião pública, já muito afetada pela insegurança causada pela criminalidade" (ALMEIDA, 2019, n. p.). Mais tarde, em fevereiro de 2018, sob articulação do então presidente Michel Temer, empossado após o impeachment, motivado por golpe jurídico e midiático (MELO et al., 2020), de Dilma Rousseff, os militares foram convocados para uma intervenção federal no combate ao tráfico de drogas no Rio de Janeiro e, no segundo semestre de 2018, o setor ganhou mais força com a possível candidatura de nomes oriundos do Exército, a exemplo do capitão reformado Jair Bolsonaro e do general da reserva Hamilton Mourão. 
Mirando as eleições para a Presidência em 2018, Jair Bolsonaro passou a significar uma imagem conservadora de homem de família e, paralelamente, foi construindo um discurso político com viés racista e cunho violento (CIOCCARI, PERSICHETTI, 2018). Para o jogo discursivo que metaforizaria a campanha do militar, a camisa da seleção brasileira passou a ser usada como símbolo bolsonarista, evocando a comunidade do verdadeiro povo brasileiro, em oposição à ideologia de gênero e à corrupção da esquerda, na busca, enfim, por uma limpeza social do Brasil, como escreve Stefanoni (2018). Dessa forma,

este discurso conservador foi formulado na linguagem do anticomunismo da Guerra Fria, que fala do perigo dos "vermelhos" e da necessidade de varrê-los do mapa político e do próprio país, vinculando-se a uma mensagem de extermínio do crime, com apelos por justiça de sua própria mão, e um discurso anticorrupção inundado de um forte antipetismo. São discursos que vão além do Brasil, mas que no gigante sul-americano estiveram ligados à tradição da desigualdade que caracteriza seu modelo de capitalismo hierárquico e autoritário. (STEFANONI, 2018, p. 7) ${ }^{3}$

Em 2018, a disputa para a Presidência foi composta por 14 candidaturas, entre elas, a de Ciro Gomes (Partido Democrático Trabalhista), Fernando Haddad (Partidos dos Trabalhadores) e Jair Bolsonaro (Partido Social Liberal). O ex-presidente Luiz Inácio Lula da Silva assumiria a chapa do PT junto a Haddad, candidato a vicepresidente, mas teve candidatura indeferida por julgamento do Tribunal Superior Eleitoral, que o considerou inelegível com base na Lei da Ficha Limpa.

Ao final do primeiro turno, Jair Bolsonaro e Fernando Haddad receberam, respectivamente, $46,03 \%$ e $29,28 \%$ dos votos, classificando-se para a última fase da eleição. No segundo turno, Bolsonaro teve vantagem, de acordo com Almeida (2019, n. p.), devido ao resultado expressivo que seu então partido, o PSL, obteve nas eleições para deputado estadual e federal e para governador; a sigla conquistou a segunda maior bancada da Câmara, com 52 deputados, ficando atrás do PT. O mesmo autor afirma que o discurso político de 
Bolsonaro significava a "condenação da corrupção praticada principalmente pelo PT, pelo PMDB e pelo PSDB", a "renovação dos quadros políticos" e a "manutenção da ordem pública com repressiva ação policial”. Com efeito, Jair Bolsonaro conquistou a vitória no pleito com $55,13 \%$ dos votos (57.796.986 votos) contra $44,87 \%$ dos votos (47.038.963 votos) para Fernando Haddad.

Contudo, no Palácio do Planalto, Bolsonaro enfrentaria a primeira crise governamental passados 50 dias desde a cerimônia de posse como $38^{\circ}$ presidente do Brasil, em $1^{\circ}$ de janeiro de 2019. A "crise das candidaturas laranjas" do PSL - a qual seria retomada pela imprensa, depois, como "Laranjal do PSL" -, foi divulgada inicialmente pelo jornal Folha de S. Paulo ${ }^{4}$ e logo investigada pela Polícia Federal, envolvendo a criação de candidaturas laranja que haviam recebido dinheiro público do partido em estados como Minas Gerais e Pernambuco.

Em um primeiro momento, a crise institucional, que voltaria a se intensificar entre os meses de outubro e novembro de 2019, levou à demissão do ministro da Secretaria Geral da Presidência Gustavo Bebianno, em 18 de fevereiro de 2019. Em outubro e novembro de 2019, a crise no PSL se agravaria, criando um forte antagonismo entre Jair Bolsonaro e o então presidente do partido, o Deputado Federal do PSL-PE Luciano Bivar, a quem Bolsonaro se referiu como cara ao pedir para correligionários esquecerem o partido, na formulação da Folha, re-publicada na epígrafe deste trabalho.

Em todo caso, é incontornável mover a noção de condição de produção para trabalhar com um objeto simbólico como o discurso político e o discurso sobre Jair Bolsonaro, pois falar, e buscar compreender, discursivamente, a política é o próprio do debate público e do espaço público enquanto espaço à e da interpretação (DIAS, 2019).

Nesse espaço público-político, no qual somos impelidos a interpretar o mundo que nos cerca, as condições de produção do discurso político, de acordo com Carlos Piovezani Filho (2007, p. 116), "englobam um grande número de razões, causas e fatores que constrangem, arcam e caracterizam o discurso", relacionando-se a "razões antropológicas e históricas próprias à sua constituição, às causas conjunturais que condicionam sua formulação simbólica" e "[a]os fatores materiais que regulam sua circulação". Por isso, as 
condições de produção, na Análise do Discurso e na análise do discurso sobre a política, se entrecruzam nas dimensões material, institucional e imaginária (ORLANDI, 2009) e não refletem uma exterioridade ao texto, mas, sim, estão inscritas no texto. São, portanto, uma condição do dizer, do sujeito atravessado pela ideologia.

\subsection{Questão e Objetivos}

Assim, pelas condições de produção que investem sentido no corpo político de Jair Bolsonaro, nos perguntamos neste trabalho como funciona o discurso sobre o atual presidente da República do Brasil? Para isso, tomamos como gesto de entrada no arquivo jornalístico o "Laranjal do PSL", esquema que culminou na saída do então partidário Jair Bolsonaro do Partido Social Liberal em novembro de 2019. Assumindo esse questionamento, o presente trabalho tem como objetivos (a) analisar o discurso sobre a política de Jair Bolsonaro na imprensa; (b) situar a metaforização de "partido" durante a crise institucional entre o PSL e a Presidência, em 2019; (c) observar o funcionamento do político no discurso sobre a política no jornalismo; e (d) compreender como instrumentos linguísticos, na relação com a normatização de manuais de redação jornalística, produzem uma normatização do dizer sobre Jair Bolsonaro no jornalismo corporativo.

\subsection{Princípios e Procedimentos}

Para compreender funcionamentos do discurso jornalístico sobre Jair Bolsonaro no discurso jornalístico, ancoramos o trabalho em princípios e procedimentos da Análise do Discurso, que surge, na leitura de Piovezani Filho (2007, p. 112), "no âmago do movimento estruturalista, sob a forma de síntese entre uma certa linguística, um certo marxismo e uma pitada de psicanálise tão ao gosto do contexto francês da segunda metade da década de 1960", tendo o discurso político como objeto principal, em um primeiro momento de disciplinarização desse saber na França, pelo grupo do filósofo Michel Pêcheux. No Brasil, a partir dos anos 1970, essa disciplina de interpretação seria atrelada fortemente à Linguística, com trabalhos fundadores de Eni Orlandi, entre outros. 
O corpus de pesquisa, por sua vez, será constituído por materiais de um dos principais sites noticiosos do país, o do jornal Folha de S. Paulo (https://www.folha.uol.com.br/), em busca que considera o sintagma nominal partido em publicações sobre o presidente Jair Bolsonaro com circulação de outubro a novembro de 2019, pois, durante esses meses, se intensificou a crise institucional no PSL e no Palácio da Alvorada, levando Jair Bolsonaro e correligionários a propor a criação de um novo partido, o Aliança pelo Brasil. Além dos textos noticiosos do website da Folha, a nossa análise considera a normatização proposta pelo "Novo Manual de Redação" da Folha de São Paulo, publicado em 1996 e com acesso gratuito para os leitores. Nesse manual, funcionando como instrumento linguístico, o período determina o uso de sinais como parênteses em formulações sobre partidos políticos, por exemplo, sendo um importante lugar de significação frente à questão e aos objetivos levantados nesta pesquisa.

Para a leitura do material, principalmente os textos jornalísticos, mobilizamos, ainda, a categoria da repetição, "um efeito material que funda comutações e variações, e assegura - sobretudo ao nível da frase escrita - o espaço de estabilidade de uma vulgata parafrástica produzida por recorrência, quer dizer, por repetição literal dessa identidade material" (PÊCHEUX, 1999, p. 53), mas fazemos intervir nesta proposição a noção de recorte, que extrapola o nível da frase escrita $\mathrm{e}$ das sequências discursivas para trabalhar com unidades ou fragmentos de uma dada situação discursiva (ORLANDI, 1984).

\section{Metaforização: entre o Político e o Discurso sobre a Política}

No projeto "Metáfora e interdiscurso", Michel Pêcheux (2015a) situa o estatuto da metáfora na Análise do Discurso a partir do funcionamento do interdiscurso ou da memória discursiva, "a condição do legível em relação ao próprio legível” (PÊCHEUX, 1999, p. 52). Assumindo que os elementos de um texto significam em uma formação discursiva dada, determinando e articulando aquilo que pode e deve ser dito pelos locutores, entendemos que esses elementos significantes estão sujeitos a se deslocar historicamente, em um gesto metaforizado, porque uma sequência discursiva, inicialmente regulada por uma formação discursiva $X$, pode ser regulada por uma formação discursiva Y, em determinadas condições de produção sócio-históricas. Esse 
princípio, que é fundante para estabelecer, desde a obra de Pêcheux (2008, 2015b), que palavras mudam de sentido no jogo de formações discursivas e que, ao mesmo tempo, o sentido sempre pode vir a ser outro, materialmente, é o que permite assumir que a metáfora, nessa leitura discursiva, está para uma perturbação no real assim como o efeito poético, o enigma e até o ato falho. "É a metáfora a responsável pelos deslizamentos dos sentidos, pela deriva, pela transferência" (ORLANDI, 2016, p. 154).

A partir da premissa de Pêcheux, deslocando da Linguística e da Psicanálise o sentido de metáfora para o entremeio da Análise do Discurso, Eni Orlandi trabalha com a noção de metaforização, indissociável, é bom lembrar, do conceito de metáfora, isto é, a possibilidade de tomar uma palavra por outra. Orlandi, em entrevista a Sarian (2020, p. 13), define, portanto, a metaforização como o modo pelo qual as palavras podem falar com outras palavras e os sentidos podem se relacionar não apenas entre si, em uma unidade ou um fragmento determinado por uma formação discursiva, mas também na relação com outros sentidos, entre a produção do mesmo (paráfrase) e do diferente (polissemia) no social. A metaforização, e não apenas a metáfora, seria, para Orlandi (2020, n. p.), uma condição para que, no discurso, "os sentidos sigam seus trajetos, irrompam, mudem, fujam", motivo pelo qual a pesquisadora argumenta que a metaforização deve ser um ponto de partida em um procedimento analítico, distinguindo sentidos, perfurando as fronteiras na e da linguagem.

Porém, como em Análise do Discurso a rede nocional está intimamente ligada, entremeada aos princípios e procedimentos, podemos relacionar a metáfora e a metaforização, enquanto condicionantes para que o discurso produza efeitos de sentido para locutores, ao político, isto é, ao

fato de que os sentidos são divididos, não são os mesmos para todo mundo, embora 'pareçam' os mesmos. Essa divisão tem a ver com o fato de que vivemos em uma sociedade que é estruturada pela divisão e por relações de poder que significam estas divisões (ORLANDI, 2006, p. 12, grifo nosso). 
Assim, se a língua precisa fazer sentido para o sujeito, ela está sujeita a falhas e à divisão dos sentidos (ORLANDI, 2016).

O sujeito da Análise do Discurso, lembramos, não é tomado como "eu-consciência mestre do sentido", nas palavras de Pêcheux (2015a, p. 156), mas está assujeitado ao discurso: "da noção da subjetividade ou intersubjetividade passamos assim a de assujeitamento. $\mathrm{O}$ efeito-sujeito aparece então como o resultado do processo de assujeitamento e, em particular, do assujeitamento discursivo". Então, apesar de haver efeitosujeito, produzindo, pela ideologia, o efeito de evidência e de unicidade do sentido (sentido já-lá e sempre-lá para o sujeito), não podemos negar a incontornável possibilidade de o sentido (na "relação a", em uma formulação) vir a ser outro.

Pensando as relações linguageiras entre o político e a política, Freda Indursky (2002) aponta, por outro lado, a circulação do discurso social como o lugar onde o político se constrói, remetendo-se aos três momentos de produção do discurso, seja a constituição, a formulação e a circulação (ORLANDI, 1996). "O político é resultado da trama de diferentes processos discursivos atravessados pelo interdiscurso e recortados por diferentes formações discursivas. Ou seja, para a análise do discurso, o que conta não é a política, mas o político" (INDURSKY, 2002 , p. 117). Para nós, no entanto, com este trabalho que mobiliza o político no discurso sobre a política de Jair Bolsonaro, é importante colocar na nossa conta tanto o político quanto a política na linguagem, visto que a análise se propõe a investigar as formas materiais que inscrevem as práticas discursivas político-ideológicas na sociedade, assumindo, também, que o trabalho de análise produz efeitos na política (MARIANI, 1996).

Em resumo, o que nos interessa e que nos move à questão de pesquisa aqui é pensar não apenas o atravessamento do discurso nas dimensões do fenômeno político, como propõe outro analista do discurso, Patrick Charaudeau ${ }^{5}$, no seu "O discurso político", mas analisar a relação entre o político e a política no tocante ao público, já que o público é significado, como sugere Cristiane Dias (2019), na e pela divisão dos sentidos por gestos de interpretação, no debate que coloca posições em disputa pelo bem comum. A política demanda a dimensão pública do espaço comum, estruturada na língua pela divisão dos sentidos. E a Análise do Discurso toma partido, incidindo na esfera política pela produção do trabalho intelectual, na medida em que coloca 
a ideologia na relação constitutiva do tripé linguagem, sujeito e história, para interpretar, sob a égide da ética ${ }^{6}$, o modo como os sentidos da política se constituem, afetados pela dispersão do político no discurso social. Espaço público do sentido e espacialização do sentido (de) público, na encruzilhada em que o político e a política se laçam.

\section{Discurso sobre Jair Bolsonaro e Personalização da Política}

O discurso sobre a política implica o funcionamento do político, pois a política, na disputa significante pelo bem comum, pelo que é considerado público pelos cidadãos, se estrutura em/por uma sociedade dividida, materializando a divisão dos sentidos nas discursividades. Tendo esse princípio, do entrelaçamento do político na política e, aqui, especificamente, na política de Jair Bolsonaro, podemos olhar o corpus (discurso jornalístico), destacando reportagens que circularam na imprensa nacional entre outubro e novembro de 2019 sobre as turbulências entre o Palácio do Planalto e o Partido Social Liberal.

Após a divulgação das candidaturas laranjas do PSL pelos jornais, no início do governo Bolsonaro, o imbróglio entre o presidente e os seus correligionários voltaria a se intensificar, por exemplo, com a repercussão de um áudio vazado em que o à época líder do PSL na Câmara dos Deputados, o Delegado Waldir, chamou Bolsonaro de vagabundo e ameaçou implodir o presidente ${ }^{7}$.

R1: O líder do PSL na Câmara, Delegado Waldir (GO), voltou atrás depois de ser gravado em reunião do partido dizendo que implodiria o presidente Jair Bolsonaro. 'Isso já passou. Nós somos Bolsonaro. Somos que nem mulher traída, apanha, mas mesmo assim volta ao aconchego', afirmou nesta quinta-feira (17) (BOLDRINI, BRANT, 2019, n. p.).

R2: O presidente Jair Bolsonaro afirmou que não pretende sair do PSL, mas que, caso saia, levará consigo a maioria do partido (...). "E eu não posso ficar num partido se nós não tomarmos conhecimento de tudo que acontece lá. Porque qualquer caso envolvendo alguém do PSL no Brasil, quem é o responsável? Eu. Eu nem conheço o cara, nunca vi o vereador, o deputado 
estadual, ou aquele filiado e vêm pra cima de mim", afirmou. (SE..., 2019, n. p.)

R3: Dono da segunda maior bancada na Câmara, com 53 deputados, o PSL vive uma guerra aberta pelo controle do partido que envolve diretamente o presidente Jair Bolsonaro e alguns dos principais integrantes de sua base no Congresso. De um lado, estão aliados a Bolsonaro; do outro, parlamentares alinhados com o fundador e presidente da sigla, o deputado Luciano Bivar (PE), que abriu espaço para o então presidenciável em 2018 disputar a eleição. A cisão entre os dois grupos, que já era presente, ganhou contornos explosivos depois que Bolsonaro falou a um apoiador que Bivar está "queimado pra caramba" (SAIBA..., 2019, n. p.).

$\mathrm{R} 1$, portanto, formula sobre o momento em que o Delegado Waldir, representante da Bancada do Boi, da Bíblia e da Bala, volta atrás, afirmando que "isso já passou", referindo-se à ameaça de implodir $o$ presidente. Na mesma formulação, que se sustenta pela antecipação (funcionamento da argumentação) de que o leitor sabe que o presidente Jair Bolsonaro era coligado ao PSL, o Delegado Waldir tenta reforçar a união dos correligionários do Partido Social Liberal, frente a qualquer rumor de racha no grupo, argumentando que "nós somos Bolsonaro" e que, em tom misógino, "somos que nem mulher traída, apanha, mas mesmo assim volta ao aconchego".

No entanto, apesar de em R1 simbolizar uma tentativa de trégua, por parte do então líder do PSL na Câmara, R2 divulga uma hipótese ("caso [Bolsonaro] saia [do PSL]") em relação a uma saída do presidente da República da sigla pela qual se elegeu. Nessa reportagem, o presidente tenta se desresponsabilizar (ou desestabilizar a sua responsabilidade enquanto presidente ligado a um partido político) por "qualquer caso envolvendo alguém do PSL no Brasil", justificando que, apesar de nunca ter visto "aquele filiado", a responsabilidade sobre o "caso" (de corrupção?) cairia em cima dele, motivo pelo qual o presidente Jair Bolsonaro deveria ter "conhecimento de tudo que acontece lá" para permanecer naquele partido.

Concomitantemente, no início do mês de outubro de 2019, Jair Bolsonaro e 21 deputados encaminharam um pedido à direção do PSL 
pedindo a prestação de contas do partido. Bolsonaro também tentou substituir o líder do partido na Câmara após divulgação do áudio em tom de ameaça, mas o presidente do PSL e deputado federal por Pernambuco, Luciano Bivar, contra-atacou com a destituição de Eduardo Bolsonaro e Flávio Bolsonaro do comando dos diretórios do PSL em São Paulo e no Rio, respectivamente. Jair Bolsonaro, enfim, decidiu retirar a deputada Joice Hasselmann (SP), também do PSL, da liderança do governo no Congresso; Hasselmann apoiava a permanência do Delegado Waldir enquanto líder do PSL na Câmara.

Chegamos, com isso, à situação que descreve R3, sobre a "guerra aberta" no PSL. Ainda que essa reportagem escreva sobre uma lista de "bolsonaristas", como Eduardo Bolsonaro (SP), o deputado federal Major Vitor Hugo (GO) e o senador Flávio Bolsonaro (RJ), também se formula sobre os "bivaristas", como o Delegado Waldir (GO) e a deputada federal Joice Hasselmann (SP). Pelo funcionamento do discurso jornalístico, tecendo a narratividade dos "fatos", esse texto reconstitui uma "linha do tempo" desde a denúncia do ministro do Turismo, Marcelo Álvaro Antônio, denunciado sob acusação de organizar esquema de candidaturas laranja no PSL de Minas Gerais nas eleições de 2018, até a escolha de Bivar para destituir Eduardo e Flávio Bolsonaro da direção do PSL em SP e RJ.

O PSL, retomado em R3 por ser "dono da segunda maior bancada da Câmara", se metaforiza para uma espécie de trincheira, em que estariam, lado a lado, os "aliados de Bolsonaro" e os "parlamentares alinhados com o fundador e presidente da sigla, o deputado Luciano Bivar". A formulação aponta que essa "cisão" (de um lado, bolsonaristas; de outro, bivaristas) "já era presente”, mas teria ganhado "contornos explosivos", mantendo o tom bélico ("guerra aberta"), no momento em que Jair Bolsonaro falou em um evento que Luciano Bivar estava "queimado pra caramba" (ver a reportagem na epígrafe deste trabalho).

R4: Ao deixar a China, o presidente Jair Bolsonaro afirmou que pode se tornar "um presidente sem partido" se a crise no PSL não se resolver. "Eu posso ser um presidente sem partido. Tanto faz eu estar com partido ou sem partido", afirmou neste sábado (27) pela manhã — sexta (26) à noite no Brasil. A legislação determina que políticos (deputados, senadores, prefeitos, 
governadores) podem ficar sem partido depois de eleitos. No caso dos deputados, se houver troca da legenda, eles podem perder o mandato. A declaração, que ainda é uma hipótese, vai ao encontro das expectativas do eleitorado mais fiel a Bolsonaro, que é crítico da atuação dos partidos em geral. (LANDIM, 2019a, n. p.)

R5: "O ideal agora é como se fossem gêmeos xifópagos [ligados entre si por uma parte do corpo]. Precisa separar. Cada um segue seu destino." Essa foi a declaração do presidente Jair Bolsonaro ao comentar a crise no PSL (...). Segundo ele, um bom nome para a agremiação seria Partido da Defesa Nacional ou PDN. "É um nome bonito, né? Tem que ser um nome que agregue", disse. (PINTO, BIN, 2019, n. p.)

R6: Em publicação em uma rede social, o presidente Jair Bolsonaro (PSL) se comparou a um leão acossado por hienas em meio às vitórias da esquerda e manifestações em países da América Latina. Entre as hienas exibidas no vídeo compartilhado pelo presidente aparecem o STF (Supremo Tribunal Federal), o PSL, partidos de esquerda como PT e PSOL, a CNBB (Conferência Nacional dos Bispos do Brasil) e veículos de imprensa, incluindo a Folha. (LANDIM, 2019b, n. p.)

R7: O presidente Jair Bolsonaro marcou uma reunião na tarde desta terça-feira (12) com o grupo de deputados bolsonaristas do PSL para informar que decidiu deixar a sigla. No encontro, que será realizado no Palácio do Planalto, ele deve comunicar que pretende ficar, pelo menos no curto prazo, sem partido. (...) A decisão passa pela definição de um caminho jurídico para que o grupo bolsonarista deixe o PSL sem perder o mandato parlamentar. (BOLSONARO..., 2019, n. p.).

A "cisão" entre Bolsonaro/"bolsonaristas" e o PSL/"bivaristas" é formulada em R4 como uma hipótese ("ainda"), com base na declaração do presidente, que falou que poderia se tornar um presidente sem partido e que "tanto faz eu estar com partido ou sem partido", ainda que o Brasil seja uma república democrática partidarista. O texto 
jornalístico, diante da declaração de Bolsonaro e das condições de produção da política brasileira, explica que "a Legislação determina que políticos (deputados, senadores, prefeitos, governadores) podem ficar sem partido depois de eleitos" e determina que o gesto de Bolsonaro faz um aceno ao eleitorado "crítico da atuação dos partidos em geral".

Já R5, pela imagem dos "gêmeos xifópagos" (que, apesar das duas cabeças, dividem o mesmo corpo), aprofunda a declaração de Bolsonaro feita em R4, com uma aspa do presidente em que ele cita que "precisa separar [do PSL]. Cada um segue seu destino". Nessa formulação, Jair Bolsonaro também sugere um "bom nome" para um suposto partido, o "Partido da Defesa Nacional ou PDN" - a bandeira de um nacionalismo foi um dos pilares da vitória de Bolsonaro em 2018; ao mesmo tempo, pretender a defesa nacional implica afirmar que a nação está em perigo e implica colocar Bolsonaro e seus apoiadores enquanto únicos autorizados a defender o Brasil desse "outro" ameaçador -, sobre o qual diz ser um nome "bonito" e que "tem que ser um nome que agregue". No deslize de R4 para R5, metaforizando o sentido de partido, temos a posição de que tanto faz o presidente estar em um partido para uma tentativa de criação de um novo partido, para o qual seria preciso uma sigla, ou um "nome", que "agregue" (uma contraposição à "cisão", a uma "guerra aberta", no discurso bolsonarista em relação ao PSL naquele momento).

Em R6, na reportagem também divulgada durante a viagem de Bolsonaro ao Oriente, o presidente se utiliza de outra imagem, a do leão ( o rei da selva), para se mostrar "acossado por hienas", seja o Supremo Tribunal Federal, o próprio PSL, os partidos de esquerda e a imprensa. Nesta formulação, o PSL aparece inscrito entre parênteses associado, como aposto, ao presidente; esta é a primeira vez entre os recortes aqui apresentados que isso ocorre, seguindo, inclusive, a norma do "Novo Manual de Redação" da Folha de S. Paulo (1996, n. p.), que rege o uso de parênteses 8 para "informar o partido e Estado de um político"; analisaremos melhor a questão da normatização do discurso jornalístico adiante.

Ao final, em R7, Bolsonaro promete oficializar a saída do PSL, em reunião com o "grupo de deputados bolsonaristas do PSL", e também afirma que "pretende ficar, pelo menos no curto prazo, sem partido". O texto também aponta para um imbróglio institucional, pela "definição de um caminho jurídico para que o grupo bolsonarista deixe o PSL sem 
perder o mandato parlamentar", uma vez que deputados que trocam de partido após eleitos podem perder o mandato, segundo a Legislação.

Na passagem de R6 para R7, e em retrospecto aos outros recortes, é importante entender a noção de personalização na política contemporânea (PIOVEZANI FILHO, 2007, p. 121), a partir da qual pode se assumir um certo apagamento das rivalidades no campo institucional e uma marcação da personalidade, em um embate que metaforiza o público e o privado na política partidária. A partir dessa ideia, podemos compreender como o PSL se metaforiza ora para o "lado" "bivarista", ora para a ala "bolsonarista", girando o tema público em torno de duas figuras políticas, ainda que haja uma justificativa na "função pública eletiva [que] emerge, sob a forma de um 'nós' ou da impessoalidade de uma instituição" para legitimar a ação de um partido (ver R1), por exemplo. E podemos entender, por outro lado, como Bolsonaro (sem partido) tenta capitanear, após a oficial saída do PSL, parlamentares para um novo partido, ainda que para o presidente fosse um pormenor (tanto faz, tanto fez) estar associado a uma sigla.

R8: O presidente Jair Bolsonaro negou neste sábado (23) que o número eleitoral 38 escolhido para o partido que pretende criar, Aliança pelo Brasil, tenha relação com o calibre de revólver. Ele disse que a opção se refere à sua posição no cargo. (...) No evento de apresentação, a Aliança pelo Brasil recebeu uma obra feita de cartuchos de bala com seu nome e símbolo. A sigla, que ainda vive incertezas sobre a sua viabilidade, tem um forte apelo à defesa do porte de armas e ao discurso de cunho religioso (BARBON, 2019, n. p.)

R9: A Aliança Pelo Brasil, partido que o presidente Jair Bolsonaro pretende fundar, se apresenta como um instrumento para "livrar o país dos larápios, dos espertos, dos demagogos e dos traidores". Em manifesto divulgado nesta terça-feira (12), a nova sigla é lançada como "uma nova e verdadeira atitude de aliados [de Bolsonaro]" e como o sonho e a inspiração de pessoas leais ao presidente. (ARBEX, 2019, n. p.). 
Por sua vez, R8 reporta uma fala de Jair Bolsonaro sobre o novo partido que pretende criar, após a saída do PSL, o "Aliança Pelo Brasil" (inicialmente, lembramos, a sugestão do nome do partido era Partido da Defesa Nacional; o sintagma nominal "partido" é silenciado pela nova proposta de sigla). Nessa reportagem, o político nega que o número escolhido (38) para representar o Aliança pelo Brasil "tenha relação com o calibre de revólver", mas, sim, teria que ver com "sua posição no cargo", já que Bolsonaro foi o $38^{\circ}$ presidente da República do Brasil. Com esse gesto, Bolsonaro orienta a interpretação do número 38, atrelado ao (Partido) Aliança pelo Brasil, com um "forte apelo à defesa do porte de armas", para centralizar a pauta no seu corpo político, investido de sentidos de presidente, em uma personalização não apenas da pauta de criação de um partido, mas também da própria política partidária.

Nesse sentido, R9 reafirma a centralidade de Bolsonaro em relação à proposta de criação do Aliança pelo Brasil, partido que o presidente pretende fundar. Além disso, o discurso jornalístico, aí, apresenta trechos do manifesto da Aliança, metaforizando partido para um "instrumento" capaz de "livrar o país dos larápios, dos espertos, dos demagogos e dos traidores"; assim como a primeira proposta de criação do partido de Bolsonaro, o Partido da Defesa Nacional, que delimitava um "nós" e um "outro", defendendo um Brasil agregado (do verdadeiro povo brasileiro?). O novo partido, então, seria, "o sonho e a inspiração de pessoas leais ao presidente" ou, nas palavras do manifesto, "uma nova e verdadeira atitude de aliados". Uma aliança, poderíamos parafrasear, não com um partido e com uma determinada causa ideológica, mas com o $38^{\circ}$ presidente da República do Brasil, um cargo efêmero que depende, necessariamente, nos moldes atuais da Constituição Federal, da renovação do mandato político, de quatro em quatro anos, por voto popular.

\section{Normatização do Discurso Político na Imprensa}

Antes de seguir a análise do objeto específico desta pesquisa, o discurso jornalístico sobre Jair Bolsonaro e a metaforização de (sem) partido na imprensa, é importante compreender o funcionamento do "Manual de Redação" da Folha de São Paulo na normatização do discurso político nesse periódico nacional. Para dar consequência a tal 
gesto, parece fundante a noção de instrumento linguístico, descrita no célebre livro "A revolução tecnológica da gramatização". Na obra, Sylvain Auroux (1992, p. 69-70) defende que a gramática não é sinônimo de descrição da linguagem natural, pois é preciso entendê-la, em sentido forte, como instrumento linguístico, pois

do mesmo modo que um martelo prolonga o gesto da mão, transformando-o, uma gramática prolonga a fala natural e dá acesso a um corpo de regras e de formas que não figuram juntas na competência de um mesmo locutor. Isso ainda é mais verdadeiro acerca dos dicionários: qualquer que seja minha competência linguística, não domino certamente a grande quantidade de palavras que figuram nos grandes dicionários monolíngues que serão produzidos a partir do Renascimento (o contrário tornaria esses dicionários inúteis a qualquer outro fim que não fosse a aprendizagem de línguas estrangeiras). Isso significa que $o$ aparecimento dos instrumentos linguísticos não deixa intactas as práticas linguísticas humanas.

Repensando a comparação da gramática com o martelo, Sylvain Auroux (1992, p. 95), em nota explicativa do mesmo livro, considera que aquela, enquanto objeto técnico, é mais complexa do que uma simples ferramenta mecânica, já que explicita conhecimentos técnicos sobre a língua. Contudo, José Simão da Silva Sobrinho (2013, p. 311313), em uma leitura discursiva de "A revolução tecnológica da gramatização", analisa que a concepção de instrumento linguístico, "embora atenue a perspectiva mecanicista da comparação entre a gramática e o martelo, não desfaz a acepção fortemente instrumental do "instrumento linguístico", motivo pelo qual propõe que essa fundamental noção seja definida pelo vínculo com a ideologia e pelo modo como o ideológico não apenas se associa, como determina a relação entre língua, sujeito e história.

Desse modo, Sobrinho (2013) sugere um espalhamento da noção de instrumentos linguísticos, pensando, para além da gramática e do dicionário, exemplificados por Auroux (1992), o Museu da Língua 
Portuguesa, em São Paulo, como um instrumento linguístico. Esse gesto teórico e analítico abre espaço para tratar o conceito - atrelado, inicialmente, à disciplina de História das Ideias Linguísticas - na relação com os manuais de redação da imprensa, com ênfase para o "Manual de Redação" da Folha de São Paulo, jornal de onde são recortados os materiais analisados neste trabalho.

Embora Auroux (1992, p. 65) aponte o papel decisivo da imprensa, a partir do século XIX, na "estandardização" da língua nacional, com a qual "a ortografia se torna um problema, às vezes, acidamente discutido", o autor não se detém, especificamente, aos manuais de redação jornalística em seu livro. Mas, para aprofundar a questão, Telma Domingues Silva (2001, p. 276) analisa os manuais de redação dos principais jornais brasileiros, compreendendo que a corporação jornalística procura estabelecer uma normatização linguística por meio dos manuais de redação, "um conjunto de 'respostas-prontas', funcionando na empresa jornalística como uma referência para os profissionais a ela associados".

Em outro trabalho, Silva (2005) aponta, igualmente, que a necessidade de os manuais descreverem os usos da linguagem enquanto técnica arrefece uma postura crítica da organização e dos profissionais sobre como a linguagem funciona na sociedade. Já diria Auroux (1992, p. 68), contribuindo com essa discussão, que as normas, uma função da gramática no processo de gramatização, "podem ser encaradas como prescrições (diga..., não diga...; diz-se...) que não possuem nenhum valor de verdade ou como descrições (na língua L..., é enunciado correto; eles dizem...)".

Portanto, para Silva (2001, pp. 278), que lê a normatização atrelada ao processo de institucionalização do dizer, os manuais estabilizam um discurso sobre a escrita na relação entre os espaços institucionais da mídia e da escola. Nesse sentido, o "papel do manual é o de contribuir para uma imagem técnica da imprensa, identificada à produção de textos, ou seja, de determinado texto, a notícia". O "Manual de Redação" da Folha de São Paulo, de acordo com a autora, significa esse lugar institucional, acionando a mídia como detentora de um saber linguístico, com verbetes sobre objetividade e apartidarismo, por exemplo. Silva (2001, p. 282) analisa que as "entradas" relacionadas à prática jornalística no "Manual de Redação" do jornal paulista 
configuram o fazer do jornalismo, na simbolização do mundo, em três diferentes esferas:

a) a esfera ético-política, simbolizando a profissão e o lugar deontológico do jornalista;

b) a esfera estilística, propondo uma certa tipologia do texto jornalístico;

c) e a esfera gramatical, determinando a normatização da língua.

Funcionando no jornalismo corporativo brasileiro, a normatização do discurso jornalístico instrumentaliza a profissão e produz uma passagem significativa de um escritor comum para um escritor profissional, já que os manuais são dirigidos a jornalistas e a um público geral (SILVA, 2001). Os manuais de redação circulam em uma sociedade na qual, é bom lembrar, o discurso jornalístico tende a se interpor entre os fatos e o sujeito-leitor, no movimento de sentidos que produz a imprensa enquanto instituição "imparcial" e "objetiva", conforme Maraisa Lopes (2012), que também estudou a relação entre os manuais jornalísticos e os instrumentos linguísticos.

Nesse processo, a normatização do texto jornalístico seria resultado, afirma Telma Domingues Silva (2001), de uma prática de escrita especializada que, na busca por uma estandização do dizer, estabelece um conjunto de normas atravessadas pela evidência de que pode o sujeito se comunicar com clareza e modular um registro formal e informal da língua. No "Novo Manual de Redação" da Folha de São Paulo (1996, n. p.), por exemplo, um "bom” texto jornalístico é descrito pela empresa como "claro e direto", "exato e conciso" e "redigido em nível intermediário, ou seja, utilizar-se das formas mais simples admitidas pela norma culta da língua".

Por isso, "o texto jornalístico passa a se colocar como referência de escrita para o escritor comum, substituindo o texto literário, que costumeiramente aparecia em livros didáticos" (LOPES, 2012, p. 180181). Os manuais de redação, então, são produzidos pela mídia ou conglomerado midiático, "um instrumento linguístico, naquilo que tange à consulta sobre a língua", e funcionam, consistentemente, como "um instrumento tecnológico", "uma alteridade para o sujeito que dele se utiliza" (LOPES, 2012, p. 178).

Por sua vez, em instrumentos como o "Novo Manual de Redação" da Folha de São Paulo, os recortes apresentam "problemas recorrentes" 
com o uso da língua e questões referentes à construção do texto jornalístico, com destaque para a produção da notícia (SILVA, 2001). O "Novo Manual de Redação" da Folha, especificamente, se coloca como uma "obra de consulta", isto é, "capaz de resolver rapidamente dúvidas específicas, o que pode significar, diga-se, "a diferença entre uma manchete correta ou com erro de português" (FOLHA..., 1996, n. p., grifo nosso). Assim, voltando aos objetivos deste trabalho, recorremos, em um primeiro gesto, ao verbete do mesmo "Manual" sobre a ocorrência de "parênteses" em textos daquele periódico:

Parênteses - Evite em texto corrido para introdução de explicações longas. Nunca use parênteses dentro de parênteses. Use-os nas seguintes situações:

a) Indicar código telefônico de área - (061) 2233530 ;

b) Introduzir datas de nascimento de personagens da notícia - Charles Dickens (1812-1870);

c) Registrar regiões de cidades - al. Santos (região dos Jardins);

d) Dar a pronúncia de palavras estrangeiras - O presidente Eisenhower (pronuncia-se aproximadamente aisenrrauer);

e) Informar o partido e Estado de um político - $O$ deputado Gochê Lavoratto (PT-AM);

f) Para informar o Estado a que pertence uma cidade - Santa Quitéria (MA);

g) Para remeter o leitor a um texto na mesma página - (leia texto ao lado).

No verbete, situamos que o "Manual" se propõe, enquanto instrumento linguístico, a oferecer "respostas-prontas" ao sujeitojornalista ou a um público geral, em um aceno, na classificação de Silva (2005), às esferas estilística e normativa, estandizando (pelo modo imperativo, resgatando uma memória gramatical, em "Evite [parênteses] em texto corrido"; "Nunca use parênteses dentro de parênteses"; "Use-os nas seguintes situações...") o texto jornalístico que deve ser formulado e, depois, colocado em circulação na Folha de S. Paulo. Nesse excerto, ressaltamos, em especial, o que o "Manual" dispõe na letra e), seja "Informar o partido e Estado de um político - O 
deputado Gochê Lavoratto (PT-AM)", norma que se inscreve na maior parte dos recortes seguintes, na tentativa de dar conta (roteirizar, "informar") de um acontecimento discursivo, atualizando a memória (PÊCHEUX, 2015b) sobre a saída de Jair Bolsonaro do PSL, partido com o qual se elegeu Presidente da República em 2018.

R10: O julgamento de um processo que discute o repasse de dados bancários e fiscais para o Ministério Público e a polícia, sem autorização judicial prévia, foi retomado nesta quinta-feira (21) com as primeiras divergências em relação à proposta do relator, ministro Dias Toffoli. (...) $\mathrm{O}$ processo ganhou relevância política porque, no âmbito dele, Toffoli suspendeu, em julho, todas as investigações do país que usaram dados detalhados do antigo Coaf e da Receita sem autorização judicial prévia, incluindo uma apuração sobre o senador Flávio Bolsonaro (sem partido-RJ), filho do presidente Jair Bolsonaro (sem partido-RJ). (TUROLLO JR., 2019a, n. p)

R11: Desnorteado após a morte do ex-governador de Pernambuco Eduardo Campos, seu candidato à Presidência em 2014, o PSB não lançou nome ao Palácio do Planalto nas eleições de 2018 (...). Com o racha interno, o partido não apoiou formalmente candidato no primeiro turno. No segundo turno, optou por Fernando Haddad (PT) contra o atual presidente Jair Bolsonaro (ex-PSL) (SEABRA, 2019, n. p.).

R12: O ex-presidente Lula (PT) rejeitou os conselhos contra a polarização política e reforçou seu lugar na oposição ao presidente Jair Bolsonaro (sem partido). (LINHARES, 2019, n. p.)

R13: O filho do presidente Jair Bolsonaro (sem partido) é investigado pelo Ministério Público do Rio de Janeiro por um suposto esquema de rachadinha no período em que era deputado estadual. (TUROLLO JR., 2019b, n. p.).

Como o funcionamento do "Manual de Redação" se relaciona à normatização do dizer e, no caso, do texto jornalístico na Folha de S. 
Paulo, R10 é interessante para uma análise sobre como o periódico formula o acontecimento da saída de Bolsonaro do PSL, atrelando a construção preposicional "sem partido" ao nome do presidente, ao qual também vem associada à sigla "RJ", da mesma forma que o jornal anuncia outros políticos, como Flávio Bolsonaro, à época, senador pelo estado do Rio de Janeiro. Essa normatização, que metaforiza sentidos de partido na imprensa, pode evocar um equívoco, quer dizer, "a necessidade de trabalhar no ponto em que cessa a consistência da representação lógica inscrita no espaço dos 'mundos formais"” (PÊCHEUX, 2015b, p. 51).

A noção de equívoco, que nada tem a ver com o que algumas gramáticas normativas chamam de erro, é produtiva na análise desse recorte, em retomada ao "mundo formal" dos manuais de redação da imprensa, porque, diferentemente de parlamentares como deputados e senadores, o corpo político de Jair Bolsonaro não significa, nessas condições de produção, um estado da Federação ("RJ"), mas, sim, a República do Brasil enquanto Estado Federal, com suas entidades governadas autonomamente. Ainda assim, a Folha, tendo como base normativa das suas formulações jornalísticas o "Manual de Redação", simboliza Bolsonaro, na relação com o "sem partido", de tal modo. O "Manual", é preciso afirmar com Lopes (2012, p. 179), é "um objeto histórico, um objeto político", que tenta homogeneizar a língua, mas, efetivamente, não exclui da língua o seu real, em outras palavras, não prescinde a normatização estabelecida pelo "Manual" da ordem do discurso (jornalístico).

Já R11 explica (a imprensa torna o mundo compreensível para a comunidade de leitores [MARIANI, 1996]), inicialmente, o "racha interno" no Partido Socialista Brasileiro, o PSB, com "a morte do exgovernador de Pernambuco Eduardo Campos". Mas o que interessa, efetivamente, para nós nesse recorte é a construção "o atual presidente Jair Bolsonaro (ex-PSL)", que retoma a normatização do discurso da Folha de S. Paulo (ver R6), pelo funcionamento dos parênteses, seguindo o seu "Manual"; mas, nessa formulação, Jair Bolsonaro ainda aparece atrelado ao Partido Social Liberal, apesar de o prefixo "ex-", diante da sigla partidária, atualizar sentidos de "partido" e significar a saída do presidente do PSL.

Em R12, lemos o que seria a fórmula ("mundo formal", efeito da normatização pelos instrumentos linguísticos) adotada pelo jornal para 
anunciar o "presidente sem partido" - para lembrar a declaração do presidente em visita à China, em 25 de outubro de 2019, sobre desligamento do PSL. O recorte traz a formulação sobre o "expresidente Lula (PT)", na relação com um partido institucional, e o "presidente Jair Bolsonaro (sem partido)". A construção "Jair Bolsonaro (sem partido)", igualmente, ocorre em R13 (textualizando a investigação do Ministério Público do Rio de Janeiro "por um suposto esquema de rachadinha" envolvendo o "filho do presidente") e, a partir daí, se estabiliza no discurso que produz a Folha sobre Jair Bolsonaro.

Assim, a análise de R10-R13 contribui para entender como um instrumento linguístico, a exemplo do "Novo Manual de Redação" publicado pela Folha de S. Paulo e, especificamente, a "entrada" em que essa obra determina o uso de parênteses na imprensa, simboliza um acontecimento discursivo, inscrevendo nas páginas do website do periódico a saída de Jair Bolsonaro do PSL e normatizando o exercício de um presidente "sem partido".

Por outro lado, o discurso sobre Bolsonaro na imprensa, considerando o acontecimento da saída do presidente do PSL, funciona na institucionalização social dos sentidos e contribui para constituir uma memória do futuro (MARIANI, 1996), à medida que estabiliza a relação parafrástica entre o exercício da presidência e o apartidarismo. Dessa forma, a construção "Jair Bolsonaro (sem partido)" corrobora, na Folha, com as condições que elegeram Jair Bolsonaro em 2018, diante da propulsão de discursos anticorrupção (fazendo oposição aos governos petistas), contra a "velha política" (na figura de partidos tradicionais como o MDB e o PSDB) e "na tradição da desigualdade [brasileira] que caracteriza seu modelo de capitalismo hierárquico e autoritário" (STEFANONI, 2018, p. 7).

\section{Considerações Finais}

Aqui, analisamos o discurso sobre a política de Jair Bolsonaro na imprensa, sendo o corpus constituído por recortes do website da Folha de S. Paulo. Situamos, inicialmente, a metaforização (ponto de partida do procedimento analítico) de "partido" diante do acontecimento discursivo da saída de Jair Bolsonaro do PSL, entre outubro e novembro de 2019, tendo a noção de personalização na política contemporânea (PIOVEZANI FILHO, 2007) como elemento crucial inscrito nas 
formulações, pelo efeito de apagamento das rivalidades no campo institucional e pela marcação da personalidade na política partidária.

Essas condições de produção se marcam, se inscrevem em recortes que simbolizam (metaforizam) o PSL ora como "bivarista", ora como "bolsonarista", por exemplo, e nas notícias sobre a necessidade de fundação do partido de Bolsonaro, o à época chamado Aliança pelo Brasil, estabelecendo a centralidade dele em relação à proposta de criação de um partido para "pessoas leais ao presidente", capaz, portanto, de "livrar o país dos larápios, dos espertos, dos demagogos e dos traidores" (o "outro").

Compreendemos, em segundo momento, como instrumentos linguísticos, na relação com a normatização de manuais de redação jornalística, produzem uma cristalização do dizer sobre Jair Bolsonaro no jornalismo corporativo. Com a "entrada" sobre o uso de parênteses no "Novo Manual de Redação" da Folha de S. Paulo, notamos como o periódico passou a inscrever um acontecimento discursivo (PÊCHEUX, 2015b), cristalizando a construção "Jair Bolsonaro (sem partido)".

Mas, como um "Manual de Redação" é um objeto histórico (LOPES, 2012), produzindo e divulgando um determinado conhecimento linguístico, fórmulas (estandização, para usar um termo de Auroux [1992]) como "Jair Bolsonaro (sem partido)" se inscrevem na história, referindo a domínios de memórias como a demanda por apartidarismo e a ruptura com uma suposta "velha política", muito associada a partidos tradicionais na cena política do Brasil, além de apontar para uma memória do futuro (MARIANI, 1996), na escalada autoritária de um líder cada vez mais centrado em seu próprio espectro (é preciso esquecer o partido), isto é, a fabricação de um "eu" que marca, na língua, um "nós" (bolsonaristas, fiéis ao presidente) contra um "eles" (o "outro"). Daí o discurso ser esse espaço (da e à interpretação) no qual o político e a política fazem sentido, com posições ideológicas que disputam, nas formações discursivas, o bem comum.

\section{Referências}

ALMEIDA, Ronaldo de. Bolsonaro presidente: conservadorismo, evangelismo e a crise brasileira. Novos estudos CEBRAP, vol. 38, n.1, janeiro-abril, 2019.

AUROUX, Sylvain. A revolução tecnológica da gramatização. Tradução de Eni P. Orlandi. Campinas: Editora da Unicamp, 1992. 
Disponível

em:

https://edisciplinas.usp.br/pluginfile.php/353006/mod resource/conten t/1/A\%20REVOLUÇÃO\%20TECNOLÓGICA\%20DA\%20GRAMA

TIZAÇÃO.pdf. Acesso em: 01 set. 2021.

CÂMARA DOS DEPUTADOS. JAIR BOLSONARO. 201?.

Disponível em: https://www.camara.leg.br/deputados/74847/biografia. Acesso em: 01 set. 2021.

CHARAUDEAU, Patrick. O discurso político. In: EMEDIATO, Wander; MACHADO, Ida Lúcia; MENEZES, William (Org.). Análise do Discurso: gêneros, comunicação e sociedade. Belo Horizonte: Faculdade de Letras da UFMG, 2006.

CIOCCARI, Deysi; PERSICHETTI, Simonetta. Armas, ódio e espetáculo em Jair Bolsonaro. Revista ALTERJOR, ano 9, v. 2, julhodezembro de 2018.

DIAS, Cristiane. O discurso político e a política nas redes sociais: plataformas tecnológicas ou a ressignificação do espaço público. In: PRIA, Albano Dalla; KARIM, Jocineide Macedo; BRESSANIN, Joelma Aparecida; KARIM, Taisir Mahmudo (Orgs.). Estrutura, acontecimento e formação: os sentidos do político nos estudos da linguagem. Campinas: Pontes, 2019.

FOLHA DE SÃO PAUlO. Novo Manual da Redação. 1996. Disponível

em:

https://www1.folha.uol.com.br/folha/circulo/manual_redacao.htm.

Acesso em: 05 set. 2021.

INDURSKY, Freda. O entrelaçamento entre o político, o jurídico e a ética no discurso do/sobre o MST: uma questão de lugar-fronteira. Revista ANPOLL, n. 12, jan.-jun. 2002.

LOPES, Maraisa. Folha: do manual ao jornal ou do jornalístico ao pedagógico. 2012. 191 p. Tese (doutorado) - Universidade Estadual de Campinas, Instituto de Estudos da Linguagem, Campinas, SP. Disponível

em: http://www.repositorio.unicamp.br/handle/REPOSIP/270535. Acesso em: 01 set. 2021.

MARIANI, Bethania Sampaio Corrêa. O comunismo imaginário: práticas discursivas da imprensa sobre o PCB (1922 -1989). 1996. 256 f. Tese (Doutorado em Linguística) - Universidade Estadual de Campinas, Instituto de Estudos da Linguagem, Campinas, SP. 1996. 
MELO, Arthur Alves Almeida Soares de; MARINHO JÚNIOR, Itací Alves; SANTOS, João Pedro Omena dos; FRANÇA, Robson Luiz de; SANTOS, Adriana Cristina Omena dos. Transição política, golpe jurídico ou midiático parlamentar? Algumas considerações acerca do impeachment de Dilma Rousseff. Humanidades \& Tecnologia em Revista (FINOM). Ano XIV, vol. 23, abr.- jul. 2020.

ORLANDI, Eni Puccinelli. Análise de Discurso: Princípios e procedimentos. 8. ed. Campinas: Pontes, 2009.

ORLANDI, Eni Puccinelli. Discurso em Análise: sujeito sentido, ideologia. Campinas: Pontes, 2016.

ORLANDI, Eni Puccinelli; SARIAN, Maristela Cury. Entrevista com Eni Orlandi. Pensares em Revista, São Gonçalo-RJ, n. 17, p. 8-17, 2020. Disponível em: https://www.epublicacoes.uerj.br/index.php/pensaresemrevista/article/download/472 99/31843. Acesso em: 10 set. 2021.

ORLANDI, Eni. Formas de individuação do sujeito feminino e sociedade contemporânea: o caso da delinquência. In: ORLANDI, Eni (Org.). Discurso e políticas públicas urbanas: a fabricação do consenso. Campinas: RG Editora, 2006.

ORLANDI, Eni Puccinelli. Interpretação: autoria, leitura e efeitos do trabalho simbólico. Petrópolis: Ed. Vozes. 1996.

ORLANDI, Eni. Segmentar ou recortar? Linguiística: questões e controvérsias. Série Estudos 10. Curso de Letras do Centro de Ciências Humanas e Letras das Faculdades Integradas de Uberaba, 1984.

ORLANDI, Eni Puccinelli. Volatilidade da interpretação: política, imaginário e fantasia. 2020. (1h55m08s). Disponível em: https://www.youtube.com/watch?v=MjCsJxfiXtg. Acesso em: 13 set. 2021.

PÊCHEUX, Michel; HAROCHE, Claudine; HENRY, Paul. A semântica e o corte saussuriano: língua, linguagem, discurso. Tradução de Roberto Leiser Baronas e Fábio César Montanheiro. São Carlos: LINGUASAGEM, out.-nov., 2008.

PÊCHEUX, Michel. Metáfora e interdiscurso. In: Análise de Discurso: Michel Pêcheux. Textos selecionados: Eni Puccinelli Orlandi. Campinas: Pontes, 2015a.

PÊCHEUX, Michel. O Discurso: estrutura ou acontecimento. Tradução por Eni P. Orlandi. 7a edição, Campinas: Pontes, 2015 b. 
PÊCHEUX, Michel. Papel da memória. In: ACHARD, Pierre et al. Papel da memória. Tradução de José Horta Nunes. Campinas: Pontes, 1999.

PIOVEZANI FILHO, Carlos. Metamorfoses do discurso político contemporâneo: por uma nova perspectiva de análise. Revista da ABRALIN, v. 6, n. 1, pp. 111-128, jan/jun. 2007.

SILVA, Telma Domingues. A Linguística na Comunicação. Revista Rua, Campinas, n. 11, pp. 53-80, 2005.

SILVA, Telma Domingues. Os manuais da imprensa no Brasil: da redação à circulação pública. In: ORLANDI, Eni. História das ideias linguísticas: construção do saber metalinguístico e constituição da língua nacional. Campinas, SP; Cáceres, MT: Pontes/UNEMAT Editora, 2001.

STEFANONI, Pablo. Biblia, buey y bala... recargados: Jair Bolsonaro, la ola conservadora en Brasil y América Latin. Nueva Sociedad, n. 278, novembro-dezembro de 2018.

SOBRINHO, José Simão da Silva. Museu da Língua Portuguesa: instrumento linguístico em tempos da ideologia do lazer. Letras, Santa Maria, v. 23, n. 46, pp. 307-315, jan./jun. 2013.

\section{Jornais}

ARBEX, Thais. Em manifesto, partido de Bolsonaro diz querer livrar país de 'larápios' e 'traidores'. Folha de S. Paulo, São Paulo, 12 nov. 2019. Poder.

Disponível

em:

https://www1.folha.uol.com.br/poder/2019/11/em-manifesto-partidode-bolsonaro-diz-querer-livrar-pais-de-larapios-e-traidores.shtml.

Acesso em: 12 set. 2021.

BARBON, Júlia. Número 38 de partido vem de $38^{\circ}$ presidente, e não de arma, diz Bolsonaro. Folha de S. Paulo, São Paulo, 23 nov. 2019. Poder.

Disponível

em:

https://www1.folha.uol.com.br/poder/2019/11/numero-38-de-partido-

vem-de-38o-presidente-e-nao-de-arma-diz-bolsonaro.shtml. Acesso em: 11 set. 2021.

BOLDRINI, Angela; BRANT, Danielle. 'É que nem mulher traída, apanha, mas volta', diz líder do PSL em recuo sobre Bolsonaro. Folha de São Paulo, São Paulo, 17 out. 2019. Poder. Disponível em: https://www1.folha.uol.com.br/poder/2019/10/e-que-nem-mulhertraida-apanha-mas-volta-diz-lider-do-psl-em-recuo-sobrebolsonaro.shtml. Acesso em: 13 set. 2021. 
BOLSONARO marca encontro com deputados aliados para informar que deixará o PSL. Folha de S. Paulo, São Paulo, 11 nov. 2019. Poder. Disponível

em:

https://www1.folha.uol.com.br/poder/2019/11/bolsonaro-marcaencontro-com-deputados-aliados-para-informar-que-deixara-opsl.shtml. Acesso em: 12 set. 2021.

LANDIM, Raquel. 'Posso ser um presidente sem partido', diz Bolsonaro em meio ao racha do PSL. Folha de S. Paulo, São Paulo, 25 out. 2019. Poder.

Disponível

em:

https://www1.folha.uol.com.br/poder/2019/10/posso-ser-umpresidente-sem-partido-diz-bolsonaro-em-meio-ao-racha-do-psl.shtml. Acesso em: 12 set. 2021.

LANDIM, Raquel. Bolsonaro compara Supremo e PSL a hienas que o atacam. Folha de S. Paulo, São Paulo, 28 out. 2019b. Poder. Disponível em: $\quad$ https://www1.folha.uol.com.br/poder/2019/10/bolsonarocompara-supremo-e-psl-a-hienas-que-o-atacam.shtml. Acesso em: 12 set. 2021.

LINHARES, Carolina. Lula prega polarização e diz que não dá para ficar no meio do caminho. Folha de S. Paulo, São Paulo, 22 nov. 2019. Poder.

Disponível

em:

https://www1.folha.uol.com.br/poder/2019/11/lula-prega-polarizacaoe-diz-que-nao-da-para-ficar-no-meio-do-caminho.shtml. Acesso em: 12 set. 2021.

PINTO, Ana Estela de Sousa; BIN, Natasha. Bolsonaro diz que PSL é como gêmeo xifópago e melhor solução é se separar. Folha de S. Paulo, São Paulo, 28 out. 2019. Poder. Disponível em: https://www1.folha.uol.com.br/poder/2019/10/bolsonaro-diz-que-psle-como-gemeo-xifopago-e-melhor-solucao-e-se-separar.shtml. Acesso em: 12 set. 2021.

SAIBA quem está em cada lado no racha do PSL entre bolsonaristas e bivaristas. Folha de São Paulo, São Paulo, 18 out. 2019. Painel. Disponível em: https://www1.folha.uol.com.br/poder/2019/10/saibaquem-esta-em-cada-lado-no-racha-do-psl-entre-bolsonaristas-ebivaristas.shtml. Acesso em: 12 set. 2021.

SEABRA, Catia. PSB critica discursos recentes de Lula e busca se descolar do PT. Folha de São Paulo, São Paulo, 29 nov. 2019. Poder. Disponível em: https://www1.folha.uol.com.br/poder/2019/11/psb- 
critica-discursos-recentes-de-lula-e-busca-se-descolar-do-pt.shtml.

Acesso em: 01 set. 2021.

SE eu sair do PSL, maioria do partido continua comigo, diz Bolsonaro.

Folha de São Paulo, São Paulo, 17 out. 2019. Poder. Disponível em:

https://www1.folha.uol.com.br/poder/2019/10/se-eu-sair-do-psl-

maioria-do-partido-continua-comigo-diz-bolsonaro.shtml. Acesso em: 12 set. 2021.

TUROLLO JR., Reynaldo. Gilmar Mendes libera investigação sobre Flávio Bolsonaro. Folha de São Paulo, São Paulo, 29 nov. 2019b. Poder.

Disponível

em:

http://www1.folha.uol.com.br/poder/2019/11/gilmar-mendes-liberainvestigacao-sobre-flavio-bolsonaro.shtml. Acesso em: 01 set. 2021.

TUROLLO JR., Reynaldo. Proposta de Toffoli sobre dados sigilosos gera divergência no STF. Folha de São Paulo, São Paulo, 21 nov. 2019a. Poder. Disponível em: https://www1.folha.uol.com.br/poder/2019/11/proposta-de-toffolisobre-dados-sigilosos-gera-divergencia-no-stf.shtml. Acesso em: 11 set. 2021.

\section{Notas}

* Doutorando em Linguística no Instituto de Estudos da Linguagem da Universidade Estadual de Campinas (UNICAMP). Mestre em Divulgação Científica e Cultural (UNICAMP). Jornalista. E-mail: viniciusdebrito94@ gmail.com.

Junho de 2013 marca, para Almeida (2019, n. p.), "uma irrupção social de proporção e abrangência não previstas, o que gerou também a consciência na maior parte da população de que algo havia se rompido. Os mais ufanistas, à direita do cenário ideológico, ao verem as ruas cheias, disseram que o "gigante adormecido se levantou". A gerência das Jornadas de Junho, em parte, por movimentos conservadores, viria a contribuir para a maior atuação da direita no Congresso Nacional em 2014, "o que se aprofundou nas eleições de 2016, tanto nos executivos como nos legislativos municipais".

2. Antes de renunciar em 2018 ao sétimo mandato para o cargo de deputado federal pelo Rio de Janeiro, Bolsonaro passou por diversas filiações partidárias, entre elas, o Partido Democrata Cristão, de 1989 a 1991; o Partido Trabalhista Brasileiro (20032005); o Partido da Frente Liberal (2005-2005); o Partido Progressista (2005-2016); o Partido Social Cristão (2016-2018); e o Partido Social Liberal (2018), segundo a Câmara dos Deputados (201?).

3. Tradução nossa: este discurso conservador fue formulado en el lenguaje del anticomunismo de la Guerra Fría, que habla del peligro de los «rojos» y de la necesidad 
de barrerlos del mapa político y del propio país, y se anudó a un mensaje de exterminio de la delincuencia, con llamados a la justicia por mano propia, y a un discurso anticorrupción inundado de un fuerte antipetismo. Se trata de discursos que van más allá de Brasil, pero que en el gigante sudamericano se entroncaron con la tradición desigualitaria que caracterizó su modelo de capitalismo jerárquico y autoritario.

4. ver reportagem de Ranier Bragon e Camila Mattoso, de 4 de fev. de 2019, para a "Folha de S. Paulo". Disponível em: https://www1.folha.uol.com.br/poder/2019/02/ministro-de-bolsonaro-crioucandidatos-laranjas-para-desviar-recursos-na-eleicao.shtml. Acesso em: 14 set. 2021. 5. Patrick Charaudeau, apesar de estar intimamente ligado à Escola Francesa da Análise do Discurso, se diferencia, às vezes, radicalmente, da proposta teórica de Michel Pêcheux. Em "O discurso político" (2006), por exemplo, Charaudeau trabalha com a noção de ato de linguagem, que tem como princípios fundadores a alteridade, a influência e a regulação, inscrevendo o ato de linguagem em um quadro acional ou em uma praxeologia (praxis).

6. Para Orlandi (2016, pp. 156-158), a ética é um "elemento constitutivo da significação e do modo como o sujeito se produz", sendo a ética "solidária" à noção de político quando não a pensamos como uma questão individual, mas, sim, discursiva.

7. Doravante, os trechos, quando retirados dos recortes, serão aspeados no corpo do texto e os gestos de paráfrase, a partir do material recortado ou da memória discursiva, serão marcados em itálico.

8. A análise que fizemos aqui sobre a normatização da Folha de S. Paulo, por meio do seu "Manual de Redação", não esgota o funcionamento dos parênteses nos textos produzidos por esse periódico nacional. No entanto, acreditamos que, a partir do exemplar do "Novo Manual de Redação" por nós consultado, cujo material online permanece com livre acesso para os profissionais da Folha e para o público-geral, tem consistência no escopo desta pesquisa. 